\title{
Editorial
}

\section{Gram-Negative Bacillary Bacteremia and Intravenous Therapy Practices}

\author{
Issam Raad, MD, FACP, FIDSA
}

Several important studies in this issue of Infection Control and Hospital Epidemiology found associations between gram-negative bacteremia and intravenous infusion therapy in hospitals in developing countries..$^{1-3}$ Although most vascular catheter-related bloodstream infections are caused by staphylococci (ie, coagulase-negative staphylococci and Staphylococcus aureus), gram-negative bacilli have also been important causes of catheterrelated bloodstream infections in the United States and other developed countries. ${ }^{4-13}$ For example, several studies of short-term nontunneled central venous catheters found gram-negative bacilli to cause $22 \%$ to $54 \%$ of associated bloodstream infections. ${ }^{48}$ Others demonstrated that gramnegative bacilli caused $26 \%$ to $55 \%$ of long-term catheterrelated bloodstream infections, with Enterobacter and Klebsiella species being leading organisms. ${ }^{913}$

Contaminated infusate has been an important source of gram-negative bacillary bacteremias, because once introduced, these microbes can thrive in such fluids. ${ }^{14-18}$ Richards et al. report an outbreak of Klebsiella pneumoniae bacteremia among neonates in a high-risk nursery in Cali, Colombia. ${ }^{1}$ Multivariate analysis in this retrospective cohort study showed that the $K$. pneumoniae bacteremia was independently associated with blood transfusions and intravenous injections. Furthermore, surveillance cultures of the high-risk neonates showed that $61 \%$ had rectal colonization with $K$. pneumoniae. Colonized neonates were cohorted in a specific area and infection control aseptic practices were enforced. These measures led to the control of the K. pneumoniae outbreak. Molecular typing methods were not performed in the study to determine the source of the $K$. pneumoniae bloodstream infections. Therefore, it would be difficult to determine whether gastrointestinal colonization versus other sources (such as contaminated infusate) was the exact source of the outbreak. However, the authors reasonably postulate that the source of the $K$. pneumoniae outbreak was most likely a high rate of patientto-patient $K$. pneumoniae transmission coupled with suboptimal infection control practices related to intravenous catheters.

This conclusion was based on the fact that simultaneously cohorting colonized neonates and recommending improved aseptic techniques resulted in prompt resolution of the outbreak and a much lower prevalence of $K$. pneumoniae intestinal colonization (12\%). The authors concluded that, most likely, $K$. pneumoniae colonizing the infants' gastrointestinal tracts was transferred through the contaminated hands of medical personnel to the intravenous catheter insertion site or administration set. The authors acknowledged the study's limitation related to the absence of genotypic testing. However, the study has merit in showing how lapses in infection control practices including suboptimal hand hygiene might lead to epidemic infusion therapy-related bloodstream infections by spreading Enterobacteriaceae among high-risk patients in general and to their indwelling catheters in particular.

A study by Macías et al. ${ }^{2}$ complements the study by Richards et al. by providing molecular typing methods to demonstrate that the injection port of the intravenous administration set could be the potential source for infections caused by Enterobacteriaceae. They found that $70 \%$ of 251 injection ports were contaminated with microbes. Contamination with gram-negative bacilli occurred in $13.9 \%$ (with Klebsiella species accounting for $69 \%$ of the ports contaminated with gram-negative bacilli). With the use of pulsed-field gel electrophoresis, the strain of Enterobacter cloacae isolated from the infusion ports of eight patients was indistinguishable from blood culture isolates of one 
bacteremic patient, and from that patient's total parenteral nutrition fluid and intravenous fluid.

Macias et al. postulated that infusate-related bloodstream infections in their setting could be related to contamination of the injection ports of the intravenous administration sets rather than intrinsic contamination of the infusate. The authors suggested that contaminated hands of healthcare workers were likely the ultimate source of injection port contamination related to poor hand hygiene, possible contamination from inadequately chlorinated water, or both. This study supports the premise of Richards et al. that contamination of the infusion administration set could be secondary to the external transfer of gram-negative bacilli through the hands of healthcare workers from multiple contaminated sources, such as colonized high-risk patients or contaminated tap water.

The study by Nasser et $\mathrm{al}^{3}{ }^{3}$ is a vivid example of the seriousness of nosocomial gram-negative bacillary bacteremias and the importance of high-quality infection control investigations for interrupting outbreaks related to such infections. The authors report one of the largest nosocomial bacteremia outbreaks caused by Burkholderia cepacia and trace it to tap water contamination of alcohol dispensers used throughout the hospital for a variety of purposes including application to skin before catheter insertion. The authors are to be commended for this highquality study, which combines sound clinical and epidemiologic investigation with molecular typing of organisms obtained from patients and environmental sources.

Nasser et al. described 411 episodes of $B$. cepacia bacteremia occurring in 361 patients during a 7-year period. Most (98\%) of the patients had fever at the time of the positive blood cultures, and $44 \%$ had catheter-site phlebitis. $B$. cepacia has been associated with outbreaks or pseudooutbreaks related to contaminated distilled water, ${ }^{19,20}$ tap water, ${ }^{21}$ saline, ${ }^{22,23}$ and antiseptics or disinfectants. ${ }^{24-32}$ On the basis of this knowledge from the literature, the authors were able to trace these bacteremias to a contaminated tap water source, which was used to dilute a $90 \%$ ethanol solution for skin antisepsis before catheter insertion. The results of molecular typing of the organisms cultured from the tap water as well as the contaminated alcohol solution and patients' blood were found to be identical. This study is another illustration of how antiseptics used to prevent infection can become the source of a serious nosocomial gramnegative bacillary bacteremic outbreak. B. cepacia has been postulated to have the potential of surviving $70 \%$ alcohol because of its ability to hydrolyze alcohol through a lipase enzyme produced by this organism.

The three studies on nosocomial catheter-related gram-negative bacillary bacteremias published in this issue of Infection Control and Hospital Epidemiology provide the hospital epidemiologist with new insight. ${ }^{1-3}$ When approaching a cluster of gram-negative bacteremias, the hospital epidemiologist should consider multiple sources. Suboptimal intravenous therapy practices in high-risk colonized patients could be the driving force for the contamination of the intravenous administration sets, as demonstrat- ed by the studies by Richards et al. and Macias et al. Furthermore, contaminated tap water, antiseptics, or both could be a source for gram-negative bacillary bacteremic outbreaks caused by water organisms such as $B$. cepacia and should prompt appropriate investigation when seen. Whereas catheter-related bacteremias caused by staphylococci reflect the natural history of devices penetrating skin colonized with these organisms, a cluster of gram-negative catheter-related bacteremias occurring in non-neutropenic patients should be thoroughly investigated, with special attention to intravenous therapy practices.

\section{REFERENCES}

1. Richards C, Alonso-Echanove J, Caicedo Y, Jarvis WR. Klebsiella pneumoniae bloodstream infections among neonates in a high-risk nursery in Cali, Colombia. Infect Control Hosp Epidemiol 2004;25:221-225.

2. Macías AE, Muñoz JM, Herrera LE, et al. Nosocomial pediatric bacteremia: the role of intravenous set contamination in developing countries. Infect Control Hosp Epidemiol 2004;25:226-230.

3. Nasser RM, Rahi AC, Haddad MF, Daoud Z, Irani-Hakime N, Almawi WY. Outbreak of Burkholderia cepacia bacteremia traced to contaminated hospital water used for dilution of an alcohol skin antiseptic. Infect Control Hosp Epidemiol 2004;25:231-239.

4. Richet $\mathrm{H}$, Hubert B, Nitemberg G, et al. Prospective multicenter study of vascular-catheter-related complication and risk factors for positive central-catheter cultures in intensive care unit patients.J Clin Microbiol 1990;28:2520-2525

5. Sherertz RJ, Raad II, Belani A, et al. Three-year experience with sonicated vascular catheter cultures in a clinical microbiology laboratory. $J$ Clin Microbiol 1990;28:760-782.

6. Gil RT, Kruse JA, Thill-Baharozian MC, Carlson RW. Triple-vs singlelumen central venous catheters: a prospective study in a critically ill population. Arch Intern Med 1989;149:1139-1143.

7. Eyer S, Brummitt C, Crossley K, Siegel R, Cerra F. Catheter-related sepsis: prospective randomized study of three methods of long-term catheter maintenance. Crit Care Med 1990;18:1073-1079.

8. Haslett TM, Isenberg HD, Hilton E, Tucci V, Kay BG, Vellozzi EM. Microbiology of indwelling central intravascular catheters. $J$ Clin Microbiol 1988;26:696-701.

9. Groeger JS, Lucas AB, Thaler HT, et al. Infectious morbidity associated with long-term use of venous access devices in patients with cancer. Ann Intern Med 1993;119:1168-1174.

10. Decker MD, Edwards KM. Central venous catheter infections. Pediatr Clin North Am 1988;35:579-612.

11. Benezra D, Kiehn TE, Gold JW, Brown AE, Turnbull AD, Armstrong D. Prospective study of infections in indwelling central venous catheters using quantitative blood cultures. Am J Med 1988;85:495-498.

12. Rotstein C, Brock L, Roberts RS. The incidence of first Hickman catheter-related infection and predictors of catheter removal in cancer patients. Infect Control Hosp Epidemiol 1995;16:451-458.

13. Johnson PR, Decker MD, Edwards KM, Schaffner W, Wright PF. Frequency of Broviac catheter infections in pediatric oncology patients. J Infect Dis $1986 ; 154: 570-578$.

14. Maki DG. Infections due to infusion therapy. In: Bennett JV, Brachman PS, Sanford JP, eds. Hospital Infections. Boston: Little, Brown; 1992:849 892.

15. Jarvis WR, Cookson ST, Robles B. Prevention of nosocomial bloodstream infections: a national and international priority. Infect Control Hosp Epidemiol 1996;17:272-275.

16. Bennett SN, McNeill MM, Bland LA, et al. Postoperative infections traced to contamination of an intravenous anesthetic, propofol. $\mathrm{N} \mathrm{Engl} \mathrm{J}$ Med 1995;333:147-154.

17. Macias AE, Muñoz JM, Bruckner DA, et al. Parenteral infusions bacterial contamination in a multi-institutional survey in Mexico: considerations for nosocomial mortality. Am J Infect Control 1999;27:285-290.

18. Macias-Hernandez AE, Hernandez Ramos I, Muñoz Barrett JM, et al. Pediatric primary gram-negative nosocomial bacteremia: a possible relationship with infusate contamination. Infect Control Hosp Epidemiol 1996;27:276-280.

19. Buxton AE, Highsmith AK, Garner JS, et al. Contamination of intravenous infusion fluid: effects of changing administration sets. Ann Intern Med 1979;90:764-768.

20. Rapkin RH. Pseudomonas cepacia in an intensive care nursery. Pediatrics 1976;57:239-243

21. Sobel JC, Hashman N, Reinherz G, Merzbach D. Nosocomial 
Pseudomonas cepacia infection associated with chlorhexidine contamination. Am J Med 1982;73:183-186.

22. Cabrerra HA, Drake MA. An epidemic in a coronary care unit caused by Pseudomonas species. Am Soc Clin Pathol 1975;64:700-704.

23. van Laer F, Raes D, Vandamme P, et al. An outbreak of Burkholderia cepacia with septicemia on a cardiology ward. Infect Control Hosp Epidemiol 1998;19:112-113.

24. Hardy PC, Ederer GM, Matsen JM. Contamination of commercially packaged urinary catheter kits with the pseudomonad EO-1. $N$ Engl J Med 1997;282:33-35.

25. Burdon DW, Whitby JL. Contamination of hospital disinfection with Pseudomonas species. Br Med J 1967;2:153-155.

26. Craven DE, Moody B, Connolly MG, Kollisch NR, Stottmeier KD, McCabe WR. Pseudobacteremia caused by povidone-iodine solution contaminated with Pseudomonas cepacia. N Engl J Med 1981;305:621-623.
27. Berkelman RL, Lewis S, Allen JR, et al. Pseudobacteremia attributed to contamination of povidone-iodine with Pseudomonas cepacia. Ann Intern Med 1981;95:32-36.

28. Panlilo AL, Beck-Sague CM, Siegel JD, et al. Infections and pseudoinfections due to povidone-iodine solution contaminated with Pseudomonas cepacia. Clin Infect Dis 1992;14:1078-1083.

29. Phillips I, Eykyn S. Pseudomonas cepacia (multivorans) septicaemia in an intensive-care unit. Lancet 1971;1:375-377.

30. Mackel DC. Contamination of disposable catheter kits with 0-1. $N$ Engl JMed 1970;282:752-753.

31. Mitchell RG, Oxon BM, Hayward AC. Postoperative urinary-tract infections caused by contaminated irrigating fluid. Lancet 1966;1:793-795.

32. Morris S, Gibbs M, Hansman D, Smyth N, Cosh D. Contamination of aqueous dilutions of Resiguard disinfectant with Pseudomonas. Med J Aust 1976;2:110-111.

\section{Letter to the Editor}

\section{Use of an Alcohol-Based Handrub and Quality Improvement Interventions to Improve Hand Hygiene in a Russian Neonatal Intensive Care Unit}

\section{To the Editor:}

We would like to acknowledge the professional, non-salary support of Drs. Lubimova, Khrustalyeva, Tekhova, and Zueva from grant monies provided by the Swedish International Development Agency (grant no. EEC H 142) for our study recently published in Infection Control and Hospital Epidemiology. ${ }^{1}$ We would also like to acknowledge the collegial support of our project from Drs. Lars G. Burman, Anna Hambraeus, and Ingegerd Kallings and Ms. Kerstin Mannerquist. They have been a great support to infection control in Russia. Our failure to acknowledge them previously was an accidental omission that we sincerely regret.

\section{REFERENCE}

1. Brown SM, Lubimova AV, Khrustalyeva NM, et al. Use of an alcohol-based hand rub and quality improvement interventions to improve hand hygiene in a Russian neonatal intensive care unit. Infect Control Hosp Epidemiol 2003;24:172179.

Samuel M. Brown, MD, is from the Massachusetts General Hospital and the Davis Center for Russian Studies, Boston, Massachusetts.

Anna V. Lubimova, MD, Iya Tekhova, MD, and Ludmila P. Zueva, MD, are from the Infection Control Training Center and the Department of Epidemiology, Mechnikov State Medical Academy, St. Petersburg, Russia.

Natalya M. Khrustalyeva, MD, and Svetlana V. Shulaeva, RN, are from the First Children's Hospital, St. Petersburg, Russia.

Donald Goldmann, MD, and Edward J. O'Rourke, MD, are from the Children's Hospital, Boston, Massachusetts. 